\title{
EL MANTUANO Y EL MANTUANISMO EN LA HISTORIA SOCIAL DE VENEZUELA
}

El origen y desarrollo de la designación venezolana de mantuano llena gran parte de la historia social de Venezuela en, los siglos xvin y xix. Tratemos de ver su origen y trayectoria.

La voz nace en Caracas, sin duda en la primera mitad del siglo xvili, como expresión de las profundas diferencias sociales de la época, y se prolonga hasta bien entrado el siglo xix. Hoy sólo se presta a la evocación histórica.

El primer testimonio que hemos encontrado de su uso es del $\mathbf{5}$ de enero de 1752, en los Documentos relativos a la insurrección de Juan Francisco de León (ed. de Caracas, 1949). Ese día se tomó declaración, o "confesión", a Matías de Oballe, vecino de Maracay, labrador, a quien acusaban de ser "el principal concitador de los ánimos de la gente de Aragua". Oballe había recibido de un sargento llamado Peraza una carta firmada por el capitán Juan Francisco de León, pero alguien le había dicho que la firma no era auténtica (p. 171): “...fue el Confesante y le preguntó a Peraza que de quién era la firma de la carta, pues le habían dicho no era de León, a que le respondió que León tenía apoderado, y que la firma de la carta era de su apoderado, y que éste era un Mantuano, y los tenía a todos de su parte..." En la misma declaración agrega Matías de Oballe (Pp. 178-179) :

... que cuando llegó Francisco de León [hijo de Juan Francisco] a casa del confesante al pueblo de Maracay, movida conversación sobre el viaje de la Guaira, y dicho el confesante los graves costos que se habrían ocasionado a su padre, le respondió dicho Francisco no habían sido ningunos, pues todos los habían suplido los Mantuanos, y volviéndole a reconvenir el confesante que mal se compadecía los suplementos de dichos Mantuanos con el refugio que habían tomado en las iglesias al tiempo de la marcha para dicha Guaira, a que respondió dicho Francisco León que es que aquélla había sido máxima y disimulo de ellos...

Mantuanos designa ahí a los criollos nobles de Caracas, que habían apoyado - con las debidas precauciones- el movimiento de 
Juan Francisco de León contra la Compañía Guipuzcoana, y lo abandonaron totalmente en el momento de la represión. Eran los dueños de las haciendas ("la oligarquía territorial", dice Gil Fortoul), afectados por el monopolio vizcaíno. La expulsión de la Compañaía Guipuzcoana satisfacía efectivamente los anhelos de toda la clase mantuana, de todos los hacendados, y aun de todo el sector criollo, víctima de los intereses monopolistas de la Compañía. En su marcha de abril de 1749 sobre Caracas, en que llegó a la Plaza Mayor y se hizo de hecho dueño de la ciudad, Juan Francisco de León, que era canario, invocaba la representación de todos los vecinos, "Nobles y Plebeyos". El Cabildo abierto del 22 de abril de 1749, presidido por los alcaldes ordinarios D. Miguel Blanco Uribe y D. Juan Nicolás de Ponte y Solórzano, con la presencia de lo más destacado de la nobleza criolla - el Marqués de Mijares, el Marqués del Toro, el Marqués de Torrecasa, el Marqués del Valle de Santiago, y además los Blanco, los Bolívar, los Herrera, los Rivas, los Tovar, etc. (en total noventa y seis asistentes) -, había apoyado por unanimidad las demandas que "en nombre de la nobleza y de la plebe" había presentado el capitán isleño, acampado con su gente en la Plaza Mayor de Caracas. La designación de mantuano no tiene ahí, como se ve, carácter peyorativo. ¿Lo habrá tenido antes?

Luego la encontramos en un documento del 25 de febrero de 1782. El regidor del Cabildo de Caracas Francisco A. de Arrieta le escribe a Francisco de Miranda, al que trata habitualmente de hermano y amigo (Archivo de Miranda, XV, 71) : "Joseph María es el muchacho de las maiores esperanzas en la ciudad, mui amado de todos; si sale a cavallo solo, quando lo encuentran lo acompañan; hasta el provisor, clérigos, los Mantuanos me lo han pedido muchas veces". José María es su hijo, y el padre se envanece de las atenciones que con él tienen los mantuanos de Caracas.

Más adelante, el 3 de mayo de 1793, Francisco de Saavedra, que habia sido Intendente del Ejército y Real Hacienda de Venezuela (1783-1786), y fue el verdadero gestor de la creación del Real Consulado de Caracas, le escribe desde Madrid a Tomás González de Carvajal sobre las dificultades para elegir los miembros del Consulado, pues el Prior, los Cónsules, el Síndico y los Conciliarios no debían ser parientes dentro del tercer $\operatorname{grado}^{1}$ y le dice:

Es muy difícil combinar la cosa de manera que habiendo de entrar en el Consulado los sujetos distinguidos del país no resulten algunos parientes, porque los llamados alli Mantuanos están liga-

1 Véase Eduardo Arcila Farías, El Real Consulado de Caracas, pp. 21 y 236. 
dos con infinitas conexiones a causa de que a manera de los Judíos no se casan sino dentro de su tribu.

Es decir, los mantuanos constituían una especie de casta, con tendencias endogámicas: casi todos ellos estaban efectivamente emparentados entre sí ${ }^{2}$. En 1796 el Gobernador y Capitán General de Venezuela don Pedro Carbonell envió a Su Majestad un importante Memorial sobre los manejos del Regente don Antonio López Quintana, del Intendente don Esteban Fernández de León y del partido mantuano ${ }^{3}$. Denunciaba: "como si sus miras se dirigiesen a la independencia, proporcionan las cosas sobre un pie sospechoso y en que pueden fundarse terribles consecuencias". Los acusó de haber procurado formar un partido en el Ayuntamiento "por unos medios escandalosos y peligrosos, como fomentar abiertamente la división entre españoles europeos y criollos, declarándose protectores de éstos en las apariencias y seduciéndolos con utilidades y beneficios a favor de la Patria, para conseguir a su conveniencia afaccionarlos, cuyo número proyectaron aumentar incitando a los que aquí se llaman mantuanos, por medio del presbítero doctor Juan José Ignacio Moreno y don Antonio Fernández de León, a entrar en los oficios de regidores que ha mucho tiempo que están vacantes. .." Sin embargo -agregaba- "no les salieron las cosas tan bien como las habían dispuesto, a causa de haberse rematado dos oficios por sujetos no mantuanos". Entonces - relataba- intentaron fuesen electos para alcaldes ordinarios don Antonio Fernández de León y el Marqués del Toro, y explicaba:

Muchas fueron las diligencias que hicieron el doctor Moreno y los regidores nuevos del partido mantuano para conseguir esta elección, con la esperanza de las promesas del Intendente, que los ha seducido y puesto en movimiento ofreciéndoles vanamente poner

2 Hay que tener en cuenta que el Real Consulado fue un poderoso instrumento de poder político y económico de la clase mantuana. Véase, además de la obra ya citada en la nota anterior, los Documentos del Real Consulado de Caracas. Introd. de E. Arcila Farías, selección de I. Leal, Caracas, 1964. Complementaba así el poder del Cabildo. Carlos Siso, La formación del pueblo venezolano, Madrid, 1953, t. 2, p. 252, dice que después de 1810 la clase mantuana de Caracas mantuvo la supremacía sobre toda la provincia, aunque se manifestaron celos de ciudades como Coro y Maracaibo. En general, la clase mantuana pasó a un primer plano, con tendencia al mando de la provincia. Se constituyó entonces la oligarquía local o provincial. Todo siguió en manos de pocas familias. Cita el testimonio de Antonio Nicolás Briceño: siete miembros de la Junta de Caracas estaban unidos por vínculos de consanguinidad y afinidad; la de Trujillo estaba formada casi totalmente por la familia Briceño (ibid, p. 256).

3 Reproducido en Mario Briceño Iracorri, Casa-León y su tiempo, 4a ed., Caracas, 1954, pp. 73-80. 
el Cabildo en el pie antiguo, en que los europeos no tenían influjo...

\section{Otras noticias encontramos después en Humboldt ${ }^{4}$ :}

Como desde el reinado de Carlos $\mathrm{V}$ han pasado de la metrópoli a las colonias el espíritu de corporación y los rencores municipales, gustan en Cumaná y en otras ciudades comerciales de Tierra Firme de exagerar las pretensiones nobiliarias de las más ilustres familias de Caracas, designadas con el nombre de Mantuanas.

Se ve que la designación estaba reservada a las familias nobles de Caracas. Pero en realidad también en las ciudades del interior se había constituido, como en Caracas, una especie de clase hidalga, o de aristocracia más o menos cerrada, que constituía la capa superior de los blancos criollos, formada por descendientes de conquistadores, de altos funcionarios o de viejos pobladores que habían desempeñado papel importante en la vida colonial. En sus manos estaba, en casi todas partes, el gobierno municipal y la propiedad de tierras, hatos, haciendas, esclavos. El mismo Humboldt, al pasar en revista la estructura de la población colonial (lib. IV, cap. 12), caracterizaba a los mantuanos - sin darles ese nombrecomo "un corto número de familias que, en cada comuna, sea por su opulencia hereditaria, sea por su muy antiguo establecimiento en las colonias, ejercen una verdadera aristocracia municipal", celosa de sus privilegios, condecoraciones y títulos, que no querían de ningún modo compartir con los demás 5 .

Esa "aristocracia municipal" se remonta al siglo xvi. En toda la legislación de Indias hay una constante preocupación por los descendientes de los conquistadores. En igualdad de circunstancias, tenían siempre preferencia sobre los peninsulares. Una serie de cédulas reales, leyes y ordenanzas ${ }^{6}$ ordenaban que los virreyes, presidentes, oidores y demás ministros nombraran para los oficios de justicia, gobierno y administración de la Real Hlacienda, en comisiones y negocios, o en encomiendas, a personas beneméritas. La Real Cédula del 12 de diciembre de 1619, reiterando una anterior, se hace eco de la reclamación de que virreyes, presidentes, oidores,

4 Viaje a las regiones equinocciales del nuevo continente, trad. de L. Aliaraclo, Caracas, 1942. Véase lib. IV, cap. 13.

5 Humboldt había visitado la hacienda de Mocundo, de la familia Toro, en la que 230 esclavos cultivaban 77 parcelas de caña; la hacienda de Cura, del Conde de Tovar; la casa del Marqués del Toro, en Guacara, y una cantidad de haciendas de Aragua y del Tuy.

6 RichaRd KONETzKe, Colección de documentos para la historia de la for. mación social de Hispanoanérica, 1493-1810, t. 1, C.S.I.C., Madrid, 1953, números 74, 148, 169, 173, 329, 357. 
gobernadores, corregidores, etc., han llevado allegados, criados y familiares suyos para ocuparlos y enriquecerlos. Y manda que "en todos los dichos oficios, provisiones y encomiendas sean antepuestos los naturales de las Indias, hijos y nietos de los conquistadores de ellas, y lo mismo sea dicho en favor de los pobladores naturales originarios de los reinos y provincias, los cuales, como hijos patrimoniales, deben y han de ser antepuestos a todos los demás. ." En varias ocasiones los llama beneméritos.

En todo el siglo xvi los primeros conquistadores y pobladores aspiraron a crear señoríos hereditarios (de ahí el tesón con que defendieron sus encomiendas) y revivieron a su favor los viejos fueros municipales, que les concedían derechos y privilegios. Los cabildos, constituidos por ellos, fueron el centro de la vida colonial, y a veces el poder único. Sus herederos, amparados en las leyes de la Recopilación, presumieron de ser "hijosdalgo y personas nobles de linaje y solar conocido", lo mismo que los hidalgos y caballeros de la Península. Tenían la pretensión de corresponderles todos los oficios de la república y un sentimiento de superioridad sobre los funcionarios enviados por la metrópoli, a los que consideraban muchas veces advenedizos, y especialmente sobre los mercaderes peninsulares. El poder real se fraccionaba en América en una suma de poderes municipales (¿no fue esto propiamente el "feudalismo" hispanoamericano?). El Cabildo de Caracas asumió muchas veces la autoridad sobre todo el territorio, en casos de acefalía, y hasta llegó a destituir gobernadores. A ello alude el padre Blas Terrero, un criollo de Caracas, nacido en 1735 y muerto en 1802 (fue capellán de Santa Rosalía), que era enemigo de la Compañía Guipuzcoana, pero no tenía mucha simpatía por los mantuanos. En su Teatro de Venezuela y Caracas (teatro equivale ahí a 'relación sucinta de los funcionarios civiles y eclesiásticos'), escrito entre 1787 y 1800, al hablar de don Lope Carrillo y Andrade, que tomó posesión del gobierno el año 1728, dice en la edición de Caracas, 1926 (p. 146) :

Cerciorado ya Su Majestad de la insolente arrogancia con que el fanático mantuanismo, endiosado de sus alcaldías, trataba a los gobernadores que apeaban, para resumir en ellos el gobierno, haciéndolos sufrir en semejantes ocasiones las irrupciones más indignas e indecorosas al honor y al nacimiento, resuelve por su Real Cédula, capaz de sepultar en la confusión y la vergüenza a los hombres más insensatos, abrogar como abroga a los abusivos alcaldes las facultades concernientes al asunto, que con sinceridad se le habian franqueado por la Real Cédula de 18 de septiembre de 1676, nombrando para este efecto un Teniente de Gobernador y Auditor de Guerra, en quien recayesen; por ausencia o enfermedad de los gobernadores, todas las funciones del gobierno... 
Vuelve a aludir despectivamente a los mantuanos al hablar del gobernador don José Solano Bote, que tomó posesión de su cargo en 1763. Era capitán de la Real Armada, y mostró excesivo fervor por la organización de las milicias, a las que incorporó a todos los sectores de la población (p. 164): "El endiosado mantuanismo sigue al mulatismo [sic]; pero por ahora más de cumplimiento y razón de estado que por emulación. A imitación de la capital, sigue la provincia, sacrificando hasta al labrador a sus inmensas reclutas".

"El endiosado mantuanismo" o "la insolente arrogancia" del "fanático mantuanismo" parecen indicar que no tenía del todo razón Humboldt cuando creía que el progreso de la ilustración y la revolución que se operaba en las costumbres estaba haciendo desaparecer poco a poco las ofensivas distinciones entre los blancos y surgir entre ellos un sentimiento de igualdad. El blanco o espanol (también el americano se llamaba español) tenía la hegemonía política, económica y social. Formaba el núcleo gobernante y poseía casi toda la riqueza (había también caciques ricos). En las ciudades tenía la categoría de vecino, a veces equivalente de encomendero, que implicaba el derecho de tener casa, caballo, armas, participar del gobierno civil y de la milicia y de los beneficios de la instrucción y la cultura. Se distinguía por la vestimenta, el usufructo de los cargos públicos y el rechazo de las labores serviles. Ninguna de sus prerrogativas tenía exclusividad absoluta, y se distinguía en realidad por la suma de ellas.

Hay que tener en cuenta que el concepto mismo de blanco no implicó absoluta pureza de sangre en ningún momento de la historia de América. El mestizo cruzado con español se llamaba castizo; el castizo con español ya era español. Es decir, era blanco el que tenía $1 / 8$ de sangre indígena. De modo análogo, el cruce de mulato con blanco daba cuarterón; de cuarterón y blanco, quinterón; de quinterón y blanco, blanco. Es decir, era blanco el que tenía $1 / 16$ de sangre negra. Estamos, pues, bastante lejos de una concepción racista extrema.

Además, la designación de blanco fue siempre muy flexible. Humboldt observaba a principios del xIx:

En las misiones todo hombre de color que no era francamente negro como un africano, o cobrizo como un indio, se dice español; pertenece a la gente de razón, y esta razón que, hay que confesar, es a veces arrogante y perezosa, persuade a los blancos, y a los que lo creen ser, que la labranza de la tierra es cosa de esclavos.

$Y$ en otro pasaje: "Nos sorprendió ver en la Esmeralda muchos zambos y mulatos y otras gentes de color que, por vanidad, se llaman españoles y se creen blancos porque no son tan rojizos como los indios". 
En el Apure encontró Humboldt a un blanco de este tipo: era moreno negruzco y andaba casi desnudo; a su mujer la llamaba doña Isabela, a su hija doña Manuela, aunque ambas andaban también casi desnudas; decía "nosotros, caballeros blancos", y felicitaba a Humboldt por haber caido entre "gente blanca y de trato"; seguía con interés las noticias de Madrid.

Era muy apetecida la designación de blanco: "Todo blanco es caballero" llegó a decirse en las Indias. Además, las Reales Cédulas de "gracias al sacar", como veremos, facilitaban la compra de la codiciada categoría de blanco por cierta cantidad de reales de vellón ${ }^{7}$.

7 Blanco ha conservado en gran parte de América un valor económico y social. En Maria de Jorge Isaacs (Emecé, 1943, p. 136), Efraín ofrece un caballo a Tránsito para que vaya al pueblo, y ella contesta: - "Si en la provincia solamente los blancos andaban a caballo ¿no es así, padre? -Si, y los que no son blancos, cuando ya está viejos. - ¿Quién te ha dicho que no eres blanca? -pregunté a Tránsito-, y blanca como pocas. -Las que yo digo son las gentes ricas, las señoras". Lo mismo hemos tenido ocasión de observar en 1947 en los Llanos de Venezuela. En Cunaviche, por ejemplo, en las fiestas de Navidad y Año Nuevo, había un baile de los blancos y un baile de los negros. En los dos habia negros y blancos, y sobre todo tipos intermedios, pero uno era de los ricos (los amos o gente principal) y el otro de los pobres (gente subordinada, peones, servicio doméstico, etc.). En Doña Bärbara, de Rómulo Gallegos, el blancaje era "la reunión de los dueños de hatos que asisten a los rodeos, sin tomar parte en los trabajos y sólo nara vigilar sus intereses a la hora del reparto del ganado recogido" (eran unos veinte propietarios). Blancos son los ricos, los amos, independientemente del color. En El llanero en la Capital, de Daniel Mendoza, que creo que es de 1859 , Palmarote llega ante una casa y llama: "-¿Dónde están los blancos de aquí? ¿No hay quien choque el tranquero?"- Los blancos cran los dueños de casa. La oposición entre blancas y mujeres campesinas se da también en Peonía de Romero Garcia (1890). Y en El sargento Felipe, de Gonzalo Picón Febres (1809), los blancos son los muchachos alegres de la ciudad que han acudido al baile campesino para divertirse con las muchachas. Mi blanco, mi blanca, es frecuente tratamiento cariñoso (véase Aurs Gómez, Lenguaje coloquial venezolano, Cúacas, 1969, 125-126). Tambićn tiene ese sentido la frase sentenciosa, que suele decirse para que alguien no se mezcle en pleitos de gente principal o de otra clase: "Ellos son blancos, cllos se entienden". Igualmente en el Perú blancos son los que mandan. $\mathrm{Y}$ en el hampa de Guayaquil blanco es "el jefe, el superior, ei amo, el protector". Con esos mismos valores de blanco, se usaba español. Dice Salvanor ne Madariaga (Cuadro histórico de las Indias, Buenos Aires, 1945, p. 587): "El criollo, desde el casi blanco hasta el casi negro, buscaba en el nombre de español su garantía de blanco... Ann hoy los peones mejicanos que se ven a veces trabajando en los jardines burgueses de las calles de los Ángeles de California, al preguntarles de dónde son, siempre contestan: "Español", respuesta que después de más de un siglo de Independencia no puede explicarse más que por esta tradición secular que da a la palabra un sentido de blanco". Todavía cn la actualidad, entre nosotros, los indios de Maracaibo llaman español a todo el que no es indio. Joś́ Rafael Pocaterra, en Tierra del sol amada (Maracaibo, 1918), lo testimonia un par de veces: "los españoles" montan un tedolito sobre un trípode, 
La sociedad colonial estaba estructurada como un sistema sui generis de "castas" 8 , que se distinguían, aunque sin mucha rigidez, por el color: los blancos, los indios, los negros esclavos y libres y las llamadas "castas de mezcla", es decir, mulatos, zambos y mestizos, con sus variadas combinaciones, a veces englobados en el término eufemístico de pardos. La Capitanía General de Venezuela tenía, en las postrimerías del régimen colonial -nos basamos en los cálculos de Humboldt, a veces contradictorios- alrededor de 800,000 habitantes: unos 200,000 españoles americanos o criollos, que pasaban por blancos, unos 12,000 españoles europeos, unos 64,000 negros esclavos, unos 120,000 indios y algo más de 400,000 pardos $^{9}$. Los blancos constituían la capa superior, y tenían acceso,

entran por la selva abriendo picas inverosímiles y perforan la tierra desde lo alto de torres fantásticas (p. 83). Los indios guajiros usan además un sombrero español (p. 8I), que es un sombrero corriente, de alas anchas, adquirido en el comercio local. Y para justificar una venganza dicen: Español la hace, español la paga. Salvador de Madariaga ve en ese anhelo de blancura de mestizos y mulatos una de las fuerzas de unidad de las Indias hacia España, su monarquía, su Iglesia; como fuerza opuesta, la atracción de la tierra, tendiendo a la mezcla, hacia abajo, "forzando a los tres pueblos a fundir sus almas bajo la égida del amor sin ley... La savia de la tierra americana se iba elevando por la escala del color hasta el español injerto. Esta savia de la tierra laboraba también en pro de la unidad del alma de las Indias" (p. 588). La Independencia la explica como una crisis entre las dos fuerzas: el anhelo de blancura y la atracción de la tierra (p. 591). Lo mismo pasaba en todas partes. Lo confirman JoRge JUAN y ANTonio de UlLoA, en su Relación histórica, de 1748 (t. 3, lib. V. cap. 5, etc.). Y las Reflexiones sobre el estado actual de América o Cartas del Abate Prat (apud Lincoln Machado Ribas, Movimientos revolucionarios en las colonias españolas de América, Buenos Aires, 1940, pp. 131-132): "Digo siempre europeo, y no español, porque entre nosotros la palabra español es sinónimo de blanco y se da igualmente al criollo, al verdadero europeo y a cualquier otro europeo u hombre blanco. "Señor -me dijeron un día al entrar en mi casa-, un español que creo que es francés ha venido a preguntar por usted". Efectivamente, era un español francés".

8 Manuel García-Pelayo, en su Esquema general de los principios de estratificación social (hemos consultado los originales manuscritos) rechaza el término de castas para la organización colonial, y considera que hay que laablar de "estratos sociales". Claro que la designación de castas no tiene en las colonias de América el valor que alcanzó en la India, pero el término fue frecuente en la legislación colonial. De todos modos, esos "estratos" tenían un componente étnico, y el término se aplicó sobre todo a "las castas de mezcla".

9 Francisco Depons, Viaje a la parte orienial de la Tierra Firme, Caracas, 1930, p. 62, calculaba que en la Capitanía General de Caracas había, hacia 1800, 728.000 habitantes: "dos décimas partes de blancos, tres de esclavos, cuatro de manumisos o descendientes de manumisos, y el resto de indios (p. 139: 72.800 indios). La obra de Depons es de I806.-Federico Brito FigusROA, Las insurrecciones de los negros esclavos en la sociedad colonial venezolana, Caracas, 1961, p. 12, ha elaborado un cuadro hipotético de la población del período 1800-1810: pardos 407.000; blancos peninsulares y canarios 12.000; 
sin trabas, al sacerdocio, a la milicia, a la universidad, a los cargos públicos.

Pero es evidente que no todos los blancos eran iguales. Había en primer lugar la distinción, tan llena de conflictos, entre peninsulares y americanos. Y aun entre los criollos, no del todo exentos de cierta proporción de sangre india o negra, diluida a través de las generaciones, había una amplia gradación que iba desde la capa reducida de los mantuanos hasta el cuantioso sector de los blancos del estado llano, una pequeña parte de los cuales había adquirido la categoría de vecinos, pero la mayoría (seguramente los que habían caído en la miseria o en los trabajos considerados serviles) eran llamados despectivamente blancos de orilla, mezclados frecuentemente con las "castas" 10.

No había igualdad entre los blancos, muchos de los cuales, bien por su condición social o por su oficio, se veían en la necesidad de probar su limpieza de sangre para tener las prerrogativas que les correspondían. Juan Victoria Páez, el padre del general Páez, promueve expediente en 1776 para probar que es blanco y limpio de sangre, porque el alcalde de San Felipe le había prohibido llevar armas en la silla de montar, como si hubiese sido negro, zambo o mulato ${ }^{11}$. El padre de Francisco de Miranda, don Sebastián de Miranda, había sido nombrado por el Capitán General, en 1764, para regir una compañía de milicias de blancos isleños. Se mantenía con su familia "en el decente exercicio -dice la Real Cédulay comercio de una tienda de lienzos de Castilla”, hasta que se vio

blancos criollos 172.727; negros libres y manumisos 33.362; esclavos 87.800; negros cimarrones 24.000; indios tributarios 75.764; indios no tributarios 25.590; indios nómades 60.000. Total, 898.403 habitantes. Nos atenemos más bien a las cifras globales y aproximadas de Humboldt. Véase nuestra Pobla. ción indigena y el mestizaje en América, t. 1, Buenos Aires, 1954, cuadro 2 y pp. $193-195$.

10 El régimen de "castas" se combinaba con el sistema estamental de la sociedad española de la época. En la Ordenanza de Buen Gobierno de 1786 (Archivo Nacional, Caracas, Diversos, LX, 240-241), las penalidades eran distintas para los nobles y los que no lo eran.

11 Archivo Nacional, Caracas, Gobierno de la Colonia ("Limpieza de san. gre", t. 10, f. 153): "Información dada por don Juan Bitoria de Páez, hijo legítimo de don Juan José de Páez y de doña Luisa de Mendoza, sobre su limpieza de sangre. Todos vecinos de la ciudad de San Felipe. Su abuelo era Luis de Mendoza, natural de la isla de Tenerife. Su padre había sido hijo natural de don Gabriel Baptista del Campo, havido en una mujer blanca de Valencia". Se le había apercibido que no usase pistolas en la silla de montar hasta que probase que era "blanco de calidad". Se queja de ser "yo solo el blanco a quien como a negro, zambo o mulato" se le priva de ese derecho. E1 $1^{\circ}$ de agosto de 1776 el gobernador y capitán general lo autoriza y declara que no se le debía prohibir el uso de pistolas en la silla de montar y demás armas licitas y permitidas. Hay expedientes de limpieza de sangre desde 1609. 
precisado a separarse de ella ${ }^{12}$. El Ayuntamiento lo acusó de usar indebidamente las insignias y prerrogativas de su cargo (bastón y uniforme de capitán). Promovió expediente en 1769 para probar que él y su legítima mujer eran gentes bien nacidas, de sangre limpia. Carlos III, por Real Cédula del 12 de septiembre de 1770, ordenó al Ayuntamiento: "Impongo perpetuo silencio sobre la indagación de su calidad y origen, y apercibo con privación de empleo y otras severas penas a cualquiera militar y individuo de ese Ayuntamiento que por escrito o de palabra no le trate en los mis mos términos que acostumbraban anteriormente y le motegen sobre el asunto".

Como sector preeminente y representativo de los blancos, les correspondió a los mantuanos enfrentarse a los pardos, a los que tachaban de tener algún ascendiente esclavo. En Caracas, y seguramente también en las ciudades del interior (hay noticias por lo menos de Coro), se opusieron tenazmente a la Real Cédula del 10 de febrero de 1795 y a la del 3 de agosto de 1801 que concedían dispensa de la calidad de pardo o de quinterón por una suma de reales de vellón (las famosas "gracias al sacar"), y sus representantes en el Cabildo de Caracas pidieron empeñosamente que se mantuviera la prohibición del matrimonio entre blancos y personas de las "castas", y las trabas para el acceso al estado eclesiástico y a la instrucción superior. A Juan Germán Roscio, hijo de italiano y de mestiza cuarterona, le negaron el acceso al Colegio de Abogados de Caracas. José Rafael Revenga, tachado de zambo, estuvo aislado entre sus condiscípulos de la Universidad de Caracas. Vargas -dice Ángel Grisanti- estuvo a punto de ser echado del Seminario Tridentino porque no pudo probar la calidad de sus abuelos. Dice Humboldt, al caracterizar a la aristocracia municipal criolla: "más quieren ser privados de ciertos derechos, que compartirlos con los demás; y aun preferirían una dominación extranjera a la autoridad ejercida por americanos de una casta inferior; abominan toda constitución fundada en la igualdad de derechos; se espantan por sobre todo de la pérdida de esas condecoraciones y títulos que tanto trabajo les ha costado adquirir, y que forman una parte esencial de su dicha doméstica".

Entre los mantuanos ocupaban el primer lugar los pocos condes y marqueses criollos que habían comprado sus títulos con remesas de cacao ${ }^{13}$. El cacao fue la gran riqueza venezolana en los siglos xvn

12 GiL ForToul, Historia constitucional de Venezuela, 2a ed., Caracas, 1930 , t. 1 , pp. $73-74$

13 Según Vallenilla Lanz, de ahí les venía el nombre de grandes cacaos. Véase Laureano Vallenilla Lanz, "Los Marqueses de Caracas", en El Nuewo Diario, 9 de junio de 1913; Id., "Los Marqueses y los Condes de Caracas", ibid., 23 de junio de 1913. También en Cesarismo democrático, Caracas, 1952, 
y xvir. El Marqués del Toro y el Conde de San Javier eran los terratenientes más interesados en el negocio del cacao, que fue la base de las grandes fortunas de la aristocracia criolla, terrateniente y mercantil ${ }^{14}$. A fines del xviI irrumpe el café, pero queda la expresión ser un gran cacao o echárselas de gran cacco, ser un personaje importante o presumir de tal.

Venezuela tenía pocos nobles con títulos: el Marqués de Mijares, el Marqués del Valle de Santiago, el Marqués del Toro, el Conde de San Javier, el Conde de la Granja, el Conde de Tovar, el Marqués de la Ribera de Boconó y Masparro (1787). A ellos se agregó el Marqués de Casa León, un peninsular enriquecido que en 1799 solicita y obtiene un título -dice- "que lo eleve sobre el común de los mantuanos de Caracas".

En los siglos xvn y xvin la Monarquía vendía títulos nobiliarios, para acrecentar la hacienda, construir iglesias, etc. ${ }^{15}$. Dice Arcaya (Estudios de sociologia venezolana, Caracas, 1941, p. 67) que la clase mantuana (niega que fuera una aristocracia política) estaba muy lejos de ser tan rica como se cree.

De todos modos, les correspondió a los mantuanos un papel de primer orden en todas las conmociones de la vida colonial. Extinguida la Compañía Guipuzcoana, a la que se habían opuesto, los mantuanos adquirieron más conciencia de su poder. En 1779 entraron en conflicto con el Intendente Abalos, que quería imponer a los vecinos un tributo personal. El Cabildo de Caracas (y luego los cábildos del interior) protestó porque consideraba que el tributo bajaba a los vecinos al nivel de los indios tributarios. Del conflicto surgió la creación del Real Consulado ${ }^{15}$, que se instaló el 24 de noviembre en la residencia del Conde de Tovar. El 13 de julio de 1797 se descubrió la llamada conspiración de Gual y España. Manuel Gual había sido capitán del batallón veterano de Caracas, y José María España era justicia mayor del pueblo de Macuto. La conspiración respondía a los principios igualitarios de la Revolución Francesa, y propiciaba la igualdad de blancos, indios, pardos y negros, "hermanos en Jesucristo, iguales por Dios" (la escarapela de cuatro colores, blanco, azul, amarillo, encarnado, sim-

p. 49, nota 1. Véase además Ulises Rojas, "Por qué el Libertador no fue Marqués de San Luis", Juan de Castellanos, Universidad Pedagógica y Tecnológica de Colombia, Tunja, 1 (1961), pp. 107-113.

14 Arcila Farías, Comercio entre Venezuela y México, México, 1950, p. 119; también en Fconomía colonial de Venezuela, pp. 112, 119 ss.

15 Véase José Torres Revello, Crónicas del Buenos Aires colonial, Buenos Aires, 1943, pp. 267-286.

10 En la matrícula relacionada con su creación estaba representada en primer lugar toda la clase mantuana; después, la "clase de comerciantes por mayor", y finalmente "la clase de mercaderes" (véase Federico Brito Figueron, La estructura social y demográfica de Venezuela, pp. 83-84). 
bolizaba esa unión). En ella participaron blancos americanos y peninsulares (comerciantes, funcionarios, militares, marinos, sacerdotes) y también pardos (milicianos, artesanos) y esclavos. Al debelarse la conspiración, el Cuerpo de Nobles, que constaba de dos compañías, ofreció sus servicios al Capitán General; eran más de setenta los nobles de Caracas que ofrecían sus vidas y haciendas y proponían armar compañías de milicias a su costa para la defensa del gobierno (los mantuanos se alarmaron sin duda por el carácter jacobino del movimiento). Entre ellos los marqueses del Toro y Mijares, los condes de Tovar, de San Javier y de la Granja. El 17 de julio se dirigen al Gobernador y Capitán General, y el 4 de agosto de 1797 a Su Majestad:

La Nobleza de la Ciudad de Caracas, junta en cuerpo y postrada humildemente a los reales pies de Vuestra Majestad, dice: que irritado altamente su celo, y de un modo inexplicable, contra el plan de conspiración descubierto en esta capital el día 13 del pasado mes, y considerando los graves cuidados en que se hallaba el Gobierno por esta razón, ... nos presentamos apresuradamente al Capitán General, ofreciendo no sólo nuestras personas y haciendas, sino también formar en el momento compañías armadas a nuestra costa para custodia de su persona o cualesquiera otros destinos o funciones que considerase oportunas para la tranquilidad común o respeto de la pública autoridad. El vuestro Capitán General apreció y aceptó inmediatamente esta oferta, y, a su consecuencia, y en virtud de la lista que formamos, sin incluir a los oficiales que sirven en milicias regladas, aprobó y creó dos compañías del cuerpo de Nobles de esta Ciudad...

En realidad, el Gobernador y Capitán General don Pedro Carbonell veía con cierta suspicacia esa actitud de los mantuanos. Por su parte se dirigió a Su Majestad el 28 de agosto de 1797 para relatarle los acontecimientos y condenar, por segunda vez, los manejos del Regente don Antonio López Quintana, del Intendente don Esteban Fernández de León y del Cabildo; pidió especialmente se separara del Cabildo al Marqués del Toro ${ }^{17}$. Y denunciaba:

... abusando de la docilidad de los que lo firmaron, pretenden tres o cuatro faccionarios comprometer el nombre de la nobleza de esta ciudad, que suponen formada en cuerpo, sin que conste qué autoridad legítima los hubiese congregado, y tal vez sin advertir las fatales consecuencias que deben temerse de la arbitraria formación de un cuerpo político que no se halla establecido por el gobierno

17 Reproducido en Documentos relativos a la Revolución de Gual y España, Caracas, 1949, pp. 130-138. La representación de la Nobleza al Rey en pp. $96-98$. 
ni autorizado por las leyes, y más cuando ningún interés público les movió a ello y sí solo elogiar exclusivamente al Regente y su caudillo y desvanecer si podían los anteriores informes contra éste y el Intendente...

Lo mismo pasó en 1806, cuando llegó la noticia de la expedición de Miranda. Entre los firmantes figuraban algunos de los que se iban a convertir pronto en prohombres de la Revolución ${ }^{18}$. La proclama que llevaba Miranda y que lanzó en Coro el 2 de agosto de 1806 trataba de atraerse a los sectores inferiores de la población: "Que los buenos e inocentes indios, así como los bizarros pardos y morenos libres crean firmemente que somos todos conciudadanos". En su proyectado Gobierno Federal, los Cabildos debían estar integrados por un tercio escogido entre los indios y la gente de color de la Provincia. Un argumento en su contra era el apoyo de una potencia extranjera.

Por otra parte, los mantuanos estaban en conflicto con las autoridades coloniales y con la población peninsular, de comerciantes

18 Cuando desembarcó Miranda, "los sujetos decentes" de Coro se retiraron a sus haciendas o siguieron al comandante español; ni los pardos quedaron; sólo se le presentaron dos esclavos. E1 Cabildo de Caracas, el 13 de mayo de 1806, a proposición del regidor Nicolás Anzola, inició una suscripción para destruir la expedición de Miranda y premiar al que le capturase. Se recaudaron, entre los principales criollos, 19.850 pesos, que se depositaron en las cajas reales y luego se remitieron a España, "destinados a gastos de la presente guerra" (Noticias de ANDrés F. PONTE, La Revolución de Caracas y sus próceres, Caracas, 1960, p. 60). E1 20 de julio de 1808 el Marqués del Toro remitió a la Real Audiencia dos cartas que "el traidor Francisco Miranda" le había enviado a él y al Cabildo de Caracas desde Londres (véase Conjuración de 1808, n. 165; Archivo de Miranda, t. 20, pp. 321-322, 323-324), lo cual no evitó que se le enjuiciara por los acontecimientos de 1808. Aun después de 1810 la hostilidad de los mantuanos hacia Miranda continuó, y se extendió a otros sectores. Bolívar, que lo había inducido a volver a su tierra, no lo acompañó en el viaje (sin duda por prudencia). Cuando Miranda llegó a la Guaira a principios de diciembre de 1810, la Junta había dado orden de que no se le dejase desembarcar. Por fin Roscio, el 12 de diciembre, le envió la autorización de la Junta. Los funcionarios, apoyados por la mayor parte, trataron de apartar al "hijo del isleño comerciante". Miranda se incorporó a la Sociedad Patriótica, en la que, junto a muchos mantuanos y los jóvenes revolucionarios de la primera hora, actuaban algunos burgueses distinguidos por sus luces, y aun individuos del pueblo. La mayor parte de los aristócratas caraqueños no quería a Miranda, pero la mocedad ing̣uieta lo tomó como jefe. Los Toro (Francisco, Fernando y Juan Rodríguez del Toro) y su parentela eran sus enemigos. A Soublette le decía Miranda: "Usted no tiene para mí más que un defecto, y es el de ser mantuano, ạunque sólo a medias". Los conflictos entre los mantuanos y Miranda fueron una de las causas principales de la muerte de la Primera República. (Tomamos todos estos datos de Parra PÉrez, Historia de la Primera República de Venezuela, Caracas, 1939 , t. 1 , p. 19; t. 2, pp. 14, 15, 20, etc.). 
y funcionarios, a los que trataban de cerrar el acceso al Cabildo (en el remate de los cargos de cabildantes y en la elección de alcaldes y regidores se libraron las primeras batallas entre mantuanos y peninsulares). Al debilitarse el poder español se sintieron capaces de asumir la hegemonía. En 1808 tomaron la iniciativa para constituir una Junta Suprema Gubernativa, y procuraron atraerse a los otros sectores sociales (a los mercaderes españoles y criollos, y aun a los jefes de las milicias de pardos). Se dijo que se contaba con el batallón de milicias del Marqués del Toro, y con 10,000 esclavos de los valles de Aragua que apoyarían el movimiento. Pero hubo una parcialidad de oficiales y capitanes de varias compañías de pardos que se brindaron a defender con sus vidas al Soberano ${ }^{19}$. Las diversas incidencias de esta tentativa y las rivalidades entre los diversos grupos, aun entre los mantuanos mismos, se pueden ver en el volumen dedicado a la Conjuración de 1808 en Caracas $^{20}$.

En su lucha contra la dominación española, los mantuanos tuvieron que apoyarse en todos los sectores criollos, aun en los pardos, y les tocó, el 19 de abril de 1810, ser los promotores de la Revolución. El grupo dirigente de los mantuanos de Caracas, por medio del Cabildo (a él se incorporaron diputados del pueblo y diputados del clero) tomó el poder y se convirtió en Junta Suprema de las provincias de la Capitanía. Culminaba así un largo proceso. Vicente de Emparan, el último Capitán General de Venezuela, informa al Rey de los acontecimientos del 19 de abril: “...como

19 Como tentativa de atraerse a los pardos se pueden considerar las palabras de Juan Vicente Bolivar (el hermano de Simón Bolivar), que aspiraba a ser caudillo de la plebe, y decía: "Los mantuanos que quieren en esta ciudad ser nobles y poseer un influjo público, con bastantes mulatos formarían un pueblo muy respetable" (C. PArra Pérez, op. cit., t. 1, p. 235).

20 La representación fiscal, firmada el 20 de abril de 1809 por Berrío y Espejo, considera que el proyecto de constituir una Junta no era viable en ningún estado ni situación (Conjuración de 1808 en Caracas, Caracas, 1949, pp. 230-231), y resumía la situación: "La multitud de clases que constituyen los pueblos de esta parte de la América produce entre los mismos, por su representación y existencia política, obstáculos insuperables para su reunión en cuerpo. Émulas las unas de las otras, jamás querría la de los nobles admitir en su concurrencia a los del estado llano, ni éstos a la clase de pardos, ni ninguno de ellos a las otras castas, y menos a la de los esclavos. Esta diferencia de colores y condiciones produciría un choque violento con que se destruirían las partes entre sí an-/tes de formar [un cuerpo unido]; además, entre los españoles de este y el otro hemisferio, la injusta rivalidad, hija de necias preocupaciones con que se miran, y que aunque ya muy mitigada no han acabado de extinguir el esfuerzo de las leyes ni el empeño del superior gobierno, ni tantas otras razones que convencen la igualdad entre los vasallos de una propia Nación, partícipes respectivamente de unos propios derechos y privilegios. Todo esto presentaba y presentará en todo tiempo insuperables dificultades para reunirse en cuerpo y conciliar sus voluntades tan opuestas parcialidades..." 
muchos de los que en Caracas llaman mantuanos, que son la clase primera en distinción, estaban poseídos del espíritu de rebelión, dos veces intentada y desvanecida, y es de la misma, de sus partes y deudos, la oficialidad del cuerpo veterano y de las milicias, fraguaron la revolución..." Y luego agregaba, al reseñar la tumultuosa reunión del Cabildo: "los mantuanos revolucionarios me despojaron del mando, obligándome a que les transfiriese el Cabildo [sic], que hizo cabeza de la rebelión". Y les pronosticaba un porvenir aciago, pues los mulatos y negros eran diez o doce por cada blanco: "Si ya no están los mantuanos arrepentidos de su desatinada insurrección, muy poco pueden tardar en arrepentirse; pero siempre será tarde ${ }^{21}$ ".

También Vicente Basadre, Intendente del Ejército y Real Hacienda, relató los acontecimientos, y cómo a él, al Capitán General y a otros altos funcionarios, los llevaron presos y los condujeron a la Guaira:

.. cada uno llevábamos siete soldados de caballería, un militar subalterno y un caballero mantuano de Caracas, sin permitirnos la comunicación; a las siete montamos a caballo, el Auditor con dirección al Castillo del Gavilán y yo al de San Carlos, acompañado de catorce hombres de Infantería, un Subalterno y un caballero Mantuano; desde el veinte y dos de abril hasta el primero de mayo, que me tuvieron en el Castillo, se relevaban todos los días a las diez de la mañana los caballeros Mantuanos de Caracas que me custodiaban, y me decían que lo mismo se verificaba con los demás presos; dichos Señores Mantuanos no hablaban otra cosa que de su Independencia y de la alegría que había causado en toda la provincia.

La Revolución fue un proceso complejo, y no lo podemos resumir aquí. Los mantuanos creyeron que iban a mantener la República en sus manos (se apoderaron de los cabildos, de los órganos de gobierno, de los consejos de guerra, del mando de las milicias, de los tribunales de Justicia). José Domingo DíAz, en sus Recuerdos sobre la rebelión de Caracas (1962, pp. 73-74) dice:

Allí por la primera vez se vio una revolución tramada y ejecutada por las personas que más tenían que perder: por el Marqués del Toro y sus hermanos don Fernando y don José Ignacio, familia de las principales, de grandes riquezas, que merecía la primera estimación de todos los mandatarios, y que llena de un

21 La Relación de Emparan al Rey, y la versión de don Vicente Basadre que citamos después se encuentran en el volumen titulado El 19 de abril de 1810 (las citas, pp. 21-22, 23-24, 27, 42, 43, 44), Instituto Panamericano de Geografía e Historia, Caracas, 1957. 
orgullo insoportable se creía y se tenía por superior a los demás; por don Martín y don José Tovar, jóvenes hijos del Conde del mismo nombre e individuos de la casa más opulenta de Venezuela; por don Juan Vicente y don Simón de Bolívar, jóvenes de la nobleza de Caracas, el primero con 25,000 pesos de renta anual y el segundo con 20,000; por don Juan José y don Luis de Rivas, jóvenes parientes de los Condes de Tovar, y de riquezas muy considerables; por don Juan Germán Roscio, don Vicente Tejera y don Nicolás Anzola, abogados que gozaban la estimación de todos sus conciudadanos; por don Lino de Clemente, oficial retirado de la Marina española y altamente considerado de todos; por don Mariano Montilla, antiguo Guardia de Corps de S. M., y su hermano don Tomás, los jóvenes de la moda y los individuos de una casa, la primera en el lujo y esplendor; por don Juan Pablo, don Mauricio y don Ramón Ayala, oficiales del batallón veterano, estimados universalmente por la honradez de su casa y por el lustre de sus mayores; y por otros pocos de las mismas o casi iguales circustancias.

Y más adelante agregaba, apostrofando a Bolívar (pp. 213-215):

Tú y los de tu clase que formaban la nobleza de Venezuela, y que erais conocidos con el nombre de Mantuanos, gozabais para con el populacho una consideración tan elevada cual jamás tuvieron los Grandes de España en la capital del Reino. Parecía, según los actos exteriores de humillación en éste, que erais formados de otra masa, o pertenecientes a otra especie. Vuestras comunicaciones se limitaban a vosotros mismos y a los primeros magistrados, y vuestros enlaces estaban circunscritos a la misma esfera. Conservabais siempre entre vuestras habitaciones aquel aire de dignidad y circunspección que indicaba una grande elevación de vuestra clase. Entonces eran puras vuestras costumbres, honesta vuestra educación, la virtud formaba su base, el amor al Rey y la obediencia a las leyes eran inspiradas como fundamentos de vuestra sociedad, y Venezuela, bajo de estos principios, fue la mansión de la felicidad. Entonces también los jefes de la provincia y los demás magistrados civiles, militares y eclesiásticos os distinguieron de un modo cual era justo, decoroso y conveniente... Y acercándonos a tiempos más inmediatos al 19 de abril, dime, ¿̨de quién se compuso la numerosa comitiva del Capitán General don Manuel de Guevara Vasconcelos? ¿Fueron otros que los Toros, los Ibarras o, por mejor decir, los Mantuanos? ¿Quiénes concurrieron a sus númerosos convites? ¿Quiénes le acompañaban a todas partes? ¿Quién lo dirigió sino don Miguel José Sanz?

Los mantuanos mandaban las milicias, legislaban, acaparaban los cargos públicos. Pero los pardos irrumpieron desde el mismo 19 de abril, y godos (= españoles peninsulares) y patriotas tuvieron que contemporizar con ellos y tratar de ganárselos. Miranda, acep- 
tado a regañadientes por los mantuanos, muchos de los cuales se oponían a su regreso al país, no supo tampoco ganarse la confianza de los pardos, a los que consideraba "la hez del pueblo". En otros términos lo expresaba Laureano Vallenilla Lanz (Cesarismo de mocrático, p. 435): "La rebelión, que comienza como un juego de niños, dirigida por las manos finamente enguantadas del Marqués del Toro, viene a terminar sobre una gran charca de sangre y un inmenso montón de ruinas, como un potro cerril, bajo la mano áspera y brutal del llanero Páez. Desde entonces la pirámide quedó definitivamente invertida". Se había producido efectivamente una revolución social, una profunda aglutinación de clases sociales, y Páez, que había sido peón llanero, se convirtió en presidente del país, "el más rico, adulado, aplaudido y temido". En 1814 Boves acaudilla a los pardos a favor del Rey y declara la guerra a muerte a todos los blancos (con lo cual entendía los blancos patriotas). Uno de los episodios más dramáticos de esa pugna fue la ejecución del general patriota Piar, el 16 de octubre de 1817 , acusado por altos oficiales de querer sublevar a los pardos para asesinar a todos los blancos. La defensa que hizo de él el Teniente Coronel Fernando Galindo desvirtúa por completo esa acusación, a nuestro parecer. Pero su actitud representaba la hostilidad de los pardos contra los mantuanos, indudablemente peligrosa para el destino de la Revolución. Bolívar siempre temió, hasta sus últimos años (Obras, II, 158, 340,361, 479), lo que llamaba la pardocracia.

La guerra de la emancipación destruyó el viejo régimen de castas y fue igualitaria. Al discutirse la Independencia, en el primer Congreso, el 5 de julio de 1811 , don Felipe Fermín Paúl reclamó que se legislara previamente sobre la suerte de los pardos, que "confundiendo la Independencia con la licencia, la insubordinación y el libertinaje, pudiesen convertir en daño nuestro los efectos de esta Revolución". La falta de cohesión entre los patriotas y el temor a los pardos causaron la caída de "la primera República".

Pero aun consolidada la Revolución, la designación de mantuano se conservó para la gente blanca adinerada o dueña de tierras, y para los descendientes de las viejas familias (familias mantuanas), que siguieron formando en las capitales una especie de patriciado intransigente más o menos endogámico: "los mantuanos, o sea los que se consideran como patricios de Caracas", escribe el mayor holandés Van Raders el 13 de diciembre de 1829 (apud PARRA PÉrez, La Monarquia en la Gran Colombia, Madrid, 1957). En 1834 -cuenta Vallenilla Lanz, en su Cesarismo democrático- hubo mantuanos que querían excluir de la Sociedad de Amigos del País (creada por decreto de Páez el 26 de octubre de 1829) a los pardos, y la iniciativa contó con el apoyo de "El Nacional". El Consejero Lisboa, que llegó a Caracas en 1843 y escribió su Relación en 1853, 
encontraba modestia y afabilidad en "esos restos de la antigua clase hidalga". Y decía: "temo han de desaparecer en breve sumergidos en el proceloso mar de las ideas republicanas". Cuenta GonzÁlez Guinán (Historia contemporánea de Venezuela, Caracas, 1909-1925) que el 16 de mayo de 1861, al salir los diputados de la Cámara, el populacho daba vivas al general Páez e insultaba a los legisladores gobiernistas: "Sabás Antonio Páez, hijo del general, grita que prefiere el puñal de la anarquía al mando de los mantuanos".

En general los mantuanos estaban identificados con la llamada "oligarquía conservadora". Sin embargo, muchos de ellos se habían incorporado en 1840 al Partido Liberal. Antonio Leocanio GuzMáN (Datos históricos, t. 2, pp. 265-267) dice en 1869 que "las tres cuartas partes de lo que lleva el nombre de mantuanismo pertenecían a la comunión liberal". Enumera las altas clases que formaban el grupo, y dice: "Un partido que presidió el ilustre Martín Tovar y en que figuraban tantos hombres connotados y aun ilustres, ¿no éramos sino un club de facciosos?" Arcaya, que lo cita en sus Estudios de sociologia venezolana (Caracas, 1941, pp. 89-91), dice que se podía pensar que el Partido liberal era aristocrático, pues agrupaba la nobleza de la sangre, el clero y los viejos generales. Y que el de Páez, llamado conservador, era el de la democracia o la plebe.

La Revolución Federal (1859-1863) fue en gran parte una explosión contra el mantuanaje, que se consideraba equivalente de oligarquía. La lucha adquirió a veces, en algunas regiones, el carácter de las viejas "guerras de castas" contra los blancos, sobre todo los propietarios, a los que se llamaba también godos ${ }^{22}$. De ella, con sus aspiraciones, sus violencias y sus injusticias, salió una Venezuela con un nuevo sentido de democracia social, sin distinciones de color.

La designación de mantuano no ha desaparecido del todo, y se conserva sobre todo en la expresión alardear de mantuano o echárselas de mantuano: "Se las echa de mantuano, pero no es muy café con leche que digamos". Hilario Guanipa, en La trepadora, de Rómulo Gallegos, "ha podido invitar a los mantuanos de Cantarrana, porque con todos se codea y todos lo estiman". Los "mantuanos de Cantarrana" eran los vecinos ricos. En Cantaclaro aparece la mantuana - la novia de un blanco- contrapuesta a la muchacha rústica de Mal Paso, y al hablar de Juan Crisóstomo Payara, dice Rómulo Gallegos: "Gente de bien con tradición de señorío social, que en lo doméstico como en lo público daban un raro ejemplo intachable, terratenientes y comerciantes que practicaban la probidad como atributo de mantuanismo, por contraposición a la plebeya

22 Godo designó primero al español peninsular; después, al realista; finalmente, al conservador. 
y absoluta carencia de honestidad que, en lo político como en lo privado, era característica de los Jaramillos enemigos". Y en $D a^{-}$ maso Velázquez, de Antonio Arraiz, Fernando pensaba en la niña Charito "con su cutis inmaculadamente blanco y sus manos de mantuana que nunca trabajó". Luis Arturo Domínguez lo encuentra en un polo coriano: "Con mi guitarra en la mano / y mi machete liniero, / me río del pueblo entero / y de los ricos mantuanos" (en Archivos Venezolanos de Folklore, 1951, núm. 1). Es todavía frecuente en la literatura venezolana, como reminiscencia de un uso histórico. Rómulo Betancourt, en Venezuela: Política y petróleo (México, 1956, p. 823), dice: "Todavía en Venezuela se califica de mantuano, con irónica intención, a quienes conservan puntillos de orgullo racial".

Hemos visto sucintamente la trayectoria de la palabra desde el siglo xvir; detengámonos ahora en el problema de su origen. Siempre se ha relacionado mantuano con manto, y la relación nos parece evidente. Pero ¿cómo se ha producido? Mantuano no es propiamente un derivado de manto. En la España del siglo xvi llamaban manteistas a ciertos estudiantes que llevaban un gran manteo sobre los hombros, para diferenciarlos de los que usaban beca, que era un embozo de capa. En América Central llaman mantudos a los disfrazados o enmascarados. Manteistas y mantudos son derivados normales de manteo o de manto. Pero mantuano no es morfológicamente un derivado de manto (no hay en español un sufijo formativo -uano), sino de Mantua, la vieja ciudad de Italia, patria de Virgilio. Mantuano es el habitante de Mantua, y por antonomasia "el Mantuano" es Virgilio ("el cisne mantuano"). ¿Y qué tiene que ver los mantuanos de Venezuela con los habitantes de Mantua, o con Virgilio? Indudablemente nada.

Detengámonos en otra posibilidad que surge al paso. En la tradición poética española fue corriente llamar Mantua a Madrid, por una suposición, más o menos gratuita ( se remonta al parecer al seudo-Beroso, de 1498), de que en la época romana se había llamado Mantua Carpetanorum, Mantua Carpetana o Mantua Carpetanea ${ }^{23}$.

23 La identificación Madrid-Mantua es muy frecuente en la literatura española. En 1516 Pedro Mártir publica en Alcalá sus tres primeras Décadas y pone como fecha de la dedicatoria al principe Carlos: "En Mantua Carpetana, vulgo Madrid, a 30 de septiembre, año 1516" (y en la Década III, lib. X, cap. 6, dice: "Madrid, que opinamos es Mantua Carpetana"). En 1550 se encuentra en Juan Hurtado de Mendoza (en un soneto sobre los nombres de Madrid, entre ellos Mantua, llamada asi -dice- "por ser sitio dispuesto al natural pronosticar"; véase $B R A E, 37$ (1957), p. 223. Insiste en una nota: "el amplio suelo y cielo de Madrid favorece la pronosticación", p. 224). Luego en La Almudena de Lope de Vega ("Madrid, que ya en otro tiempo fue llamada Mantua"). Otros ejemplos registra Carlos Fernández Gómez, en su 
¿Pueden los mantuanos de Venezuela -designación que alude en su origen a las ínfulas suntuarias de los nobles criollos de Caracas- tener alguna relación con el uso poético de mantuanos por madrileños? Nos parece absolutamente imposible. Mantuano con el valor de madrileño no salió nunca de cierta esfera literaria, y no se ve además cómo podía aplicarse a los nobles criollos, opuestos, como hemos visto, a los peninsulares.

Hay que pensar en una derivación humorística y libre sobre manto, asociándolo con los otros usos de esa voz (mantuano 'madrileño' o Mantuano 'natural de Mantua'). Hoy mismo se le dice a veces al dormilón, aludiendo a que se le pega la manta o cobija: “'No seas mantuano!" (información del Dr. Marcos Falcón).

La asociación entre manto o manta y mantuano, no es insólita. De modo análogo, en Navarra (al menos en Arjona, según el Vocabulario navarro de Iribarren) una mantuana es una paliza o tunda, sin duda como equivalente de manteo o manteamiento ${ }^{24}$. No sabemos qué fundamento puede tener la afirmación de Julio Calcaño (El castellano en Venezuela): "Cuando los reyes de España concedían licencia de matrimonio a un noble español, si la novia era de sangre limpia, ponían la cláusula: «Por ser ella limpia de sangre y no mantuana»". Lo más probable es que se base en una información falsa o en una lectura errónea.

Pero, ¿por qué se iba a hacer un juego de palabras con manto para designar a una clase social privilegiada? Es que el manto, o

Vocabulario completo de Lope de Vega, Madrid, 1971. También en la Gala. tea de Cervantes (el pastor Damón, "de las montañas de León trae su origen, $y$ en la nombrada Mantua Carpetanea fue criado”). Además, en una serie de planos viejos. Hasta hubo, a principios del xvn, una Academia Mantuana. La Historia de Benzoni, de 1586 (lib. II, cap. 10), dice: "Didacus Gottierez Mantue Carpetane civis (Madritium vulgo vocant)". Todavía era frecuente en la poesía neoclásica. En Nicolás Fernández de Moratín, por ejemplo. A fines del xvir escribía Forner, en las Exequias de la lengua castellana: "El Padre Manzanares, el que inspira / blando acento en los cisnes mantuanos..." Sus risnes mantuanos eran los poetas madrileños, que se inspiraban a orillas del Manzanares. Ecos de ese uso llegan hasta la literatura del siglo xix (sobrevivió en la masonería y hasta alguna referencia se encuentra en Galdós). Tenemos otro testimonio importante: Mantua Carpetana es Madrid en un poema hecho en la Guayra el 30 de agosto de 1908 por Sebastián García Franco.

24 Asociación análoga se ha producido también en otras lenguas: En portugués mantuana es la mujer de mala nota, de malas costumbres: "É uma mantuana que anda metida con homem casado" (Grande enciclopedia porthguesa e brasileira), por alusión sin ducla al manto o disfraz con que a veces iba cubierta o disimulada. $Y$ es curioso que también en inglés se haya usado mantua con el valor de 'manto' (mantua silk), del francés manteau y asociación con mantua (Oxford English dictionary); todavía aparece en los diccionarios manuales (The American college dictionary, etc.), como designación de un tipo de manta. Lo usó Walter Scott: "A new mantua of genuine French silk" (Webster dictionary of the English language, ed. 1864). 
el derecho de usar manto, era un privilegio de esa clase. Desde la lejana Edad Media las autoridades de toda Europa se empeñaron en dictar ordenanzas y leyes contra el lujo externo, en parte para restringirlo, pero sobre todo para mantener visibles las diferencias sociales, y que los de abajo no vistieran mejor que los de arriba. Ciertos artículos de moda, ciertos peinados, ciertas pieles, sedas o encajes y los bordados de oro y plata, estaban prohibidos a las clases inferiores ${ }^{25}$. Un ejemplo entre mil: en 1751, en Dresde, dos criadas fueron duramente castigadas por haberse atrevido a entrar con miriñaque en una iglesia, cosa que sólo podían hacer las señoras ${ }^{26}$. Durante siglos se suceden por todos los países las llamadas leyes suntuarias. De ahí surgió, tardíamente, por un lado la librea $y$ por el otro el uniforme militar.

En América las distinciones de clase del régimen colonial implicaron en seguida distinciones en la vestimenta. Una real cédula del 11 de febrero de 1571 (Recopilación de Leyes de Indias, lib. VII, título $\mathrm{V}$, ley 28 ) prescribía:

Ninguna negra libre o esclava, ni mulata, traiga oro, perlas ni seda; pero si la negra o mulata libre fuere casada con español, pueda traer unos zarcillos de oro con perlas y una gargantilla, y en la saya un ribete de terciopelo, y no puedan traer ni traigan mantos de burato ni de otra tela, salvo mantellinas que lleguen poco más abajo de la cintura, pena de que se les quiten y pierdan las joyas de oro, vestidos de seda y mantos que trajeren.

Ya se ve que el manto de las señoras caracterizaba a una clase social. En la España medieval el manto había sido característica de caballeros y de nobles (se usaban mantos forrados de armiño, seda, etc.), y de ahí la vieja expresión gente de manto para designar al señorío. Un romance anónimo del siglo xvu relata las bodas del Cid:

25 En el Archivo Nacional de Caracas, Diversos, XLV, 177, hay un "Testimonio de las diligencias obradas en virtud de la orden del Teniente Justicia Mayor de la ciudad de Coro para que las zambas y mulatas cesen en el uso de alfombras y petates" (S. Ana de Coro, 24 de julio de 1774). El Ayuntamiento de Mérida prohibió a los que no fueran blancos "usar guantes, quitasol o paraguas, tapete o alfombra y palos con virolas de plata" (JuAN Besson, Historia del Estado Zulia, 1943, p. 287). Parece testimonio de 1777.

26 La moda. Historia del traje en Europa desde los origenes del cristianismo hasta nuestros dias, por Max von BowHN, t. 4 (siglo xvm), Barcelona, 1928, p. 176. En la allea sajona de Dennschütz dos aldeanas fueron procesadas por llevar miriñaque. En cambio, las criadas de Paris ya lo llevaban en 1720 hasta para ir al mercado. En la Nueva España hubo también limitaciones en la vestimenta y el lujo, aun para los españoles, a fin de evitar la ostentación y el derroche; véase la Premática de los vestidos en las Décadas de Antonio de Herrera (Década III, lib. V, cap. 2). 
Más atrás viene Jimena trabándola el Rey la mano, con la Reina su madrina, y con la gente de manto ${ }^{2 \pi}$.

Cuando Don Quijote Ilega al palacio de los Duques, dos hermosas doncellas se le acercan y echan sobre sus hombros "un gran manto de finísima escarlata" (II, 31). Ya no era prenda de uso cotidiano, y sólo la conservaban -dice Covarrubias- las órdenes militares. Pero había pasado al uso de las señoras, que se cubrían con él la cabeza al salir a la calle. Cuando la dueña Dolorida suspira, gime y llora ante él, Don Quijote hace que se descubra y quite "el manto de sobre la faz Ilorosa" (II, 52). EI Diccionario de Autoridades describía ese manto: "Cierta especie de velo u cobertura que se hace regularmente de seda, con que las mujeres se cubren para salir de casa, el cual baja desde la cabeza hasta la cintura, donde se ata con una cinta"... Las pragmáticas de Madrid, en 1586-1588 -dice Amezúa- prohibieron que las mujeres anduviesen embozadas en sus mantos (Quevedo escribió con ese motivo su romance satírico, "Confesión que hacen los mantos de sus culpas". Pero no surtieron efecto, y las tapadas dieron todavía tema al teatro de Calderón. Para evitar confusiones embarazosas, las Ordenanzas de Sevilla del siglo xvi obligaban a las mujeres públicas que anduviesen por la ciudad a cubrirse con mantos negros doblados. Por eso se las llamaba $-\mathrm{y}$ aun se las Ilama hoy, dice Rodríguez Marín- damas de medio manto.

El manto de las señoras vino a América. En Lima se asoció con la saya, y acompañó a las tapadas desde el siglo XvI hasta mediados del xix. Fray Antonio Vázquez de Espinosa, en su Compendio y descripción de las Indias Occidentales, escrito hacia 1628, dice que en la Asunción del Paraguay había 650 vecinos españoles y " 11,000 mujeres de manto, como se tomó por fe y testimonio de los padrones de los curas el año de 1627". Sus cifras son siempre exageradas: era demasiado 11,000 mujeres de manto para sólo 650 vecinos, o sea cabezas de familia. De todos modos nos testimonia el uso de mujeres de manto como una designación empleada ya en los padrones eclesiásticos.

La vestimenta era clasificadora, y en algunas partes de América se conservan todavía hoy distinciones más o menos rígidas (Redfield las ha estudiado en Yucatán). En los cuadros de mestizaje del siglo xvir aparece la española (así se llamaba a la blanca, aunque fuese americana) ataviada con un manto negro que le cubría la cabeza y le llegaba hasta más abajo de la cintura; podía arrebo-

27 Romancero general de RIvadenerRA, t. 10 , núm. 740 , p. 487 ; Romances escogidos, Coll. Publiće sous la direction de E. Mérimée, Paris. 
zar en él las manos y ceñírselo al cuerpo. Las mulatas competían a veces en el lujo del manto, pero lo usaban blanco. Un inglés, Thomas Gage, que pasó por la ciudad de México hacia 1630, describe con cierto deleite la vestimenta de lujo de las mulatas:

Cuando salen, se ponen un manto blanco de linón o batista con festón de encaje ancho, que algunas se echan sobre la cabeza, y tan amplio que les cae hasta la mitad del cuerpo por detrás, de modo que se les vea cintura y cintas, y las dos puntas por delante llegan casi hasta el suelo; otras se echan estos mantos sólo a la espalda y van fanfarroneando con ellos sobre el hombro izquierdo a fin de mover mejor el brazo derecho, enseñando la manga ancha al andar.

Ese lujo no carecía de riesgos. Cuenta Concolorcorvo, en su Lazarillo, de 1773, las impresiones de su pago por Córdoba, la tradicionalista ciudad argentina:

No permiten a los esclavos, y aun a los libres que tengan mezcla de negro, usen otra ropa que la que se trabaja en el país, que es bastantemente grosera. Me contaron que recientemente se había aparecido en Córdoba cierta mulatilla muy adornada, a quien enviaron a decir las señoras se vistiese según su calidad, y, no habiendo hecho caso de esta reconvención, la dejaron descuidar, y, Ilamándola una de ellas a su casa con otro pretexto, hizo que sus criadas la desnudasen, azotasen, quemasen a su vista las galas y le vistiesen las que correspondían por su nacimiento, y sin embargo de que a la mulata no le faltaban protectores, se desapareció, por que no se repitiese la tragedia.

De aquella Córdoba colonial trae algunas noticias más José Luis LanuzA (Morenada, Buenos Aires, 1967, p. 35). Una mulata se había casado con el español Juan Bruno, y parece que los humos de ella escandalizaron a la "nobleza" de la ciudad, y tuvo que intervenir el Cabildo:

La nobleza de esta ciudad - dice un acta del Cabildo, de 1746 le requirió, así de hombres como de señoras, para que se le mandase al dicho Bruno que no saliese la dicha su mujer a la iglesia, ni a la calle con manto ni vestuario de seda, ni alfombra..., por ser este vestuario divisa de la nobleza, y ser esta mulata criada en las esquinas de la plaza como su familia materna y hermanas, y que, de no hacerlo así, resultaría gran perjuicio al gobierno de la república y se originarían varios escándalos, pues pasaría la nobleza a hacer su demostración con la dicha mulata...

Y luego agrega el mismo José Luis Lanuza:

Parece que no bastó el apercibimiento del Cabildo. Eugenia u otras mulatillas continuaron escandalizando a la ciudad, vistiéndose 
de seda y haciéndose acompañar por una criadita que llevaba la alfombra a la iglesia. La solemne corporación se vio obligada a insistir -el 5 de marzo de 1750 - en sus amonestaciones. Que las mulatas, indias, mestizas ni negras se atrevieran a vestir seda ni cambray, ni a lucir encajes, ni zarcillos de oro o coral, porque se les quitarian los vestidos. Y si reincidian se las castigaría públicamente con cincuenta azotes.

A mediados del siglo xvm pasan por Cartagena de Indias Jorge Juan y Antonio de Ulloa. Hablan de las "castas" y describen la vestimenta femenina:

Aquellas que legitimamente no son blancas se ponen sobre las polleras una basquiña de tafetán de distinto color (pero nunca negro), la cual está toda picada para que se vea la de abajo, y cubren la cabeza con una como mitra de un lienzo blanco, fino y muy lleno de encajes, el cual, quedando tieso a fuerza de almidón, forma arriba una punta, que es la que corresponde a la frente: llámanle el pañito, y nunca salen fuera de las casas sin él y una mantilla terciada sobre el hombro. Las señoras y demás mujeres blancas se visten a esta moda de noche, y el traje les sienta mejor que el suyo.

Una Ordenanza de la Real Audiencia de Nueva España, de México, 14 de abril de 1612, confirmando la Ordenanza del Virrey, del 3 de junio de 1598, ordenaba: ... "que ninguna negra ni mu. lata, libre ni cautiva, pueda traer ni traiga ninguna joya de oro $\mathrm{ni}$ plata, ni perlas ni vestidos de seda de Castilla, ni mantos de seda, ni pasamanos de oro ni de plata, so pena de cien azotes y de perdimiento de los tales vestidos, joyas, perlas y lo demás..."

La sociedad, y sobre todo la sociedad femenina, era más rígida que las leyes de la metrópoli y que los funcionarios coloniales. Cuenta Arcaya que el gobernador Ricardos dispuso que el verdugo saliese cierto día por las calles de Caracas vestido de gala y con peluca, que era una de las prendas que los nobles de la época pretendían como exclusivas, para burlarse de las demandas de una señora sobre la calidad de sus hijos. A principios del siglo xIx observaba Depons en Caracas (Viaje, 393): "El traje de las mujeres, ricas o pobres [al ir a la iglesia], principalmente de las blancas, ha de ser rigurosamente negro. Consiste en basquiña y manto negros. Sólo a las esclavas se les permite el uso de mantos blancos". $Y$ continuaba: "Los mantos de gasa descubren los rasgos y frescuras de la mujer... Este traje, meramente religioso, pues se usa de modo exclusivo para asistir a los oficios divinos, hecho en seda o terciopelo, y adornado con ricas blondas, cuesta a menudo de cuatrocientos a ochocientos pesos fuertes".

Es evidente que el uso del manto como prenda de distinción de 
aquellas señoras dio el nombre a toda su clase social: los mantuanos. Con la Revolución, el manto no desapareció del todo, pero descendió de categoría. La moda, que marcha al compás de las revoluciones, lo relegó a las señoras de edad, conservadoras de la venerable tradición. El Consejero Lisboa, en 1853, decía que todavía era general en Bogotá y Quito, y frecuente en Lima. Arístides Rojas veía aún señoras de manto en Caracas a mediados del siglo pasado. En Pobre negro, de Rómulo Gallegos, que es una reconstrucción de la época de la guerra federal, la vieja esclava de los Alcorta se arrebujaba con un mantón de paño negro y largos flecos, "de los que habían sido privilegio de las amas". En los Andes venezolanos las señoras ancianas conservan el manto negro con flecos para sus lutos. Y todavía hoy, en familias tradicionales de Caracas, las personas ancianas recuerdan una expresión con que se motejaba a las señoras de ciertas infulas: " $E$ Esa es doña María ponte el manto!"

En el Perú, donde tuvo su grandeza, se transformó en manta. Todavía la describía Juan de Arona (Diccionario de peruanismos, Lima, 1883): la manta es la mitad del traje de la limeña, y las hay de espumilla, recamadas o floreadas de magníficas labores chinescas, la orilla guarnecida por una cenefa de tul negro que cae sobre la cara, constituyendo un disfraz. La compara con el manto de las chilenas (menos lujoso), la manta de las cubanas y la mantilla española ${ }^{28}$. De todos modos, decayó bastante, y hoy es de seda negra, con crespón o gasa, prenda de viejas, negras y señoras de luto. Me dice la doctora Martha Hildebrandt que hoy se llama mujer de manta a la de condición social modesta.

Desde la mantuana del siglo xvin hasta la mujer de manta de hoy, iqué vendaval de sacudidas sociales, de revoluciones, de modas! No se puede asegurar que haya desaparecido del todo el mantuanismo social. Pero, eso sí, y es un signo indudable de nuestra época: se ha producido una relativa igualación de la vestimenta.

Ángel Rosenblat

Instituto de Filología "André Bello",

Universidad Central de Venezuela.

28 Abelardo M. Gamarra, el costumbrista peruano, en Lima al comenzar el siglo $x x$ (Biblioteca Peruana de Cultura, pp. 129-132), dedica un artículo a la manta: "La manta se despide, se va, como ya se ha ido la capa". 